\title{
Passeio, passante, passeante. Uma PLATAFORMA DE ARTE E CULTURA URBANA
}

\author{
Maria da Luz Correia, Helena Pires \& Pedro Andrade
}

\begin{abstract}
RESUMO
A Passeio é uma plataforma de arte e cultura urbana, concebida no âmbito do Centro de Estudos de Comunicação e Sociedade (CECS) da Universidade do Minho. Com este projeto, através de uma metodologia qualitativa e de inspiração antropológica, fixamos o nosso olhar nas ruas da cidade - na arquitetura, no graffiti, na música, no teatro e na animação de rua, no desporto urbano, no artesanato e no comércio tradicional, na publicidade e no vitrinismo - nas suas imagens, nas suas histórias e nas ligações tecnológicas que prolongam o traçado destas ruas e destas redes. Neste artigo, a partir de uma revisão de paradigmas teóricos relativos à cultura visual, à cidade e às noções de espaço e de lugar, fixamos na figura inspiradora do flâneur, tal como esta foi descrita e problematizada pelo filósofo alemão Walter Benjamin, o ponto de partida comum deste passeio.
\end{abstract}

\section{Palavras-chave}

Cidade; cultura visual; espaço; flâneur; espaço

\begin{abstract}
Passeio (the Portuguese word for walk) is a platform of urban art and culture, conceived within the scope of the University of Minho's Communication and Society Research Centre (CECS). Using a qualitative methodology and an anthropological inspiration, this project looks at urban streets - in terms of architecture, graffiti, music, street theatre and animation, urban sports, handicrafts and traditional commerce, outdoor advertising and window-shopping - and organises its respective images and stories, focusing on the technological connections that extend the layout of these streets and networks. Based on a review of the theoretical paradigms related to visual culture, the city and notions of space and place, in this article the common point of departure for this passeio (walk) is the inspirational figure of the flâneur, as described and analysed by the German philosopher, Walter Benjamin.
\end{abstract}

\section{KEYWORDS}

City; flâneur; space; visual culture

As ruas são o apartamento do coletivo. (...) As brilhantes placas metálicas das casas de comércio são para o coletivo um décor tão valioso, ou ainda mais, que uma pintura a óleo, pendurada na sua sala, aos olhos do burguês. Walter Benjamin (1989, p. 441, M3a, 4)

O que vejo às vezes entre duas paragens de autocarro pode ser mais forte do que aquilo que vejo quando entro numa sala de exposições. (Maria Teresa Cruz, 1992, p. 52) 
A Passeio é uma plataforma de arte e cultura urbana. Com este projeto, fixamos o nosso olhar nas ruas da cidade - na arquitetura, no graffiti, tag e stencil, na música, no desporto urbano, no teatro e na animação de rua, no artesanato e no comércio tradicional, na publicidade e no vitrinismo - nas suas imagens, nas suas histórias e nas ligações tecnológicas que prolongam o traçado destas ruas e destas redes. O nosso objetivo passa por contextualizar as ações quotidianas que acontecem nas ruas da cidade - que vão desde o passo de dança do acordeonista, à pose do homem-estátua e ao pregão do comerciante - com a memória partilhada dos seus transeuntes: as recordações de estabelecimentos comerciais e lojas, as histórias de vida de artistas e comerciantes de rua, os testemunhos de minorias étnicas e culturais que habitam a cidade.

No presente artigo, retraçamos o processo de conceção desta plataforma, sintetizamos as decisões teóricas e as opções metodológicas que estão na sua base, assim como procuramos sistematizar os seus objetivos, através de três eixos de ação: a investigação e a formação, o arquivo e a divulgação, a colaboração e a extensão. Com base nas noções de cultura visual, de cidade e de espaço, elaboramos ainda um estado da arte, que conflui no reconhecimento do estatuto paradigmático e do carater inspirador de que a figura benjaminiana do flâneur se reveste na presente investigação (Benjamin, 1989, 1940/200ob). Deambulando entre as galerias comerciais, as montras e os espelhos, os panoramas e os museus de cera, o flâneur recompõe através do seu labiríntico trajeto quotidiano a complexa miríade de imagens da city, sendo por isso quer representativo do nosso entendimento de cultura visual contemporânea quer do nosso entendimento de espaço e do lugar, ambos em grande medida devedores do pensamento do filósofo alemão Walter Benjamin. Se é verdade que ruturas de natureza social, cultural e tecnológica complexificam hoje a experiência do passante que doravante deambula entre os shoppings, os parques radicais, os graffitis e os mupis ligado aos seus dispositivos móveis e às suas tecnologias ubíquas, é nosso entender que a figura do passeante, mantém ainda a sua validade epistemológica, sobretudo no quadro de uma plataforma de arte e cultura urbana'.

\section{Do MUSEU VIRTUAL DE ARTES VISUAIS À PLATAFORMA DE ARTE E CULTURA URBANA}

A Passeio é uma plataforma de arte e cultura urbana, concebida no âmbito das bases de conhecimento previstas no projeto estratégico para 2015-2020 do CECS. Com origem na proposta de constituir um museu virtual de artes visuais, este projeto, coordenado por Maria da Luz Correia e Helena Pires, começou por reposicionar-se como uma plataforma de arte e cultura urbana, através de uma dupla estratégia de fechamento e de abertura.

\footnotetext{
' Veja-se a este respeito o trabalho de Julieta Leite (2010) a propósito das mediações tecnológicas da cidade contemporânea e nomeadamente a sua metáfora da ciberflânerie.
} 


\section{DAS ARTES VISUAIS À CIDADE}

Num primeiro sentido, fechamos o universo de estudo, transitando das artes visuais nos seus tão diversos contextos e nas suas tão heterogéneas expressões, para as artes visuais em contexto urbano, delimitando essa vasta área das artes visuais com a fronteira da cidade, das suas ruas, dos seus edifícios, das suas multidões e dos meios de comunicação que os relacionam. Esta opção passou, num primeiro momento, por aquiescer a centralidade da cidade na experiência da contemporaneidade, reconhecendo a premência atual de uma cultura visual urbana, cuja emergência tem origem em grande medida numa série de acontecimentos situados no final do século XIX: a introdução de transportes como o automóvel, o surgimento de meios de comunicação o telégrafo e o telefone, e o aparecimento de formas de entretenimento e de lazer, como o cinema e a publicidade.

O frenesim das cidades, o seu "choque" no célebre diagnóstico de Walter Benjamin, descrito pelos pensadores, poetas e artistas novecentistas, e intensificado no séc. XXI com a disseminação da tecnologia digital nos mais diversos domínios da experiência quotidiana, remete-nos precisamente para a especificidade da cidade como uma arena de estímulos visuais, sonoros, tácteis e cinéticos, que condicionaria hoje a nossa vivência, nomeadamente devido ao seu poderoso aparelhamento tecnológico (Correia, 2015a, $2015 b)^{2}$. Com efeito, num momento em que os elos sociais estão progressivamente sujeitos a interfaces digitais, de que os ecrãs táteis dos nossos dispositivos móveis são um exemplo, é também objetivo da Passeio questionar a natureza híbrida da experiência do lugar, que se consubstancia no trânsito quotidiano pelas ruas da cidade e nas conversas diárias entre os seus habitantes, mas que é também prolongada na navegação diária pela Web e nos diálogos ininterruptos entre os seus utilizadores.

\section{DAS ARTES VISUAIS À CULTURA}

Num segundo sentido, abrimos o universo de estudo proposto, prolongando a ideia de arte na ideia de cultura, e procurando fazer prevalecer as dimensões histórica e política da experiência quotidiana da cidade sobre a sua dimensão estética. Por um lado, visamos, com esta abertura, furtar-nos a uma moderna conceção autónoma da arte e às categorias abstratas e dicotomias estéticas que legitimam os seus processos de institucionalização, separando estavelmente a arte da não arte, o high do low, o erudito e o popular, o original da cópia, ou ainda o museu da rua. Por outro lado, queremos com a ênfase na dimensão histórica, afastar-nos de uma pós-moderna sensação difusa da arte que tende a disseminar a perspetiva estética em todos os domínios da experiência, e a apreciar a totalidade da vida social como uma obra de arte3.

\footnotetext{
${ }^{2}$ A especificidade da cidade como experiência multissensorial far-nos-ia também abdicar do limite do visual, da visão e das visualidades inicialmente contido na proposta de um museu virtual de artes visuais, e que rapidamente se viu convertido no projeto de uma plataforma de arte e cultura urbana.

3 Sintetizamos aqui as críticas à autonomia da arte estética e à ambição expansionista do dispositivo estético, detalhadas em Correia (2013, pp. 215-223).
} 
Assim, optamos por um entendimento de cultura que a relaciona estreitamente com os fragmentos e as desordens da experiência, esquivando-nos, de algum modo, aos riscos de totalização e de ordenação que José Bragança de Miranda (2007) e Moisés de Lemos Martins (2011) atribuem à ideia corrente de cultura. Diga-se que este nosso entendimento é em grande medida devedor da conceção dual de cultura proposta pela filósofa Hannah Arendt (1972), ou ainda da proposta de uma "cultura em ação" lançada por Antonin Artaud (1964). Artaud como Arendt convergem num entendimento dialético da cultura, enquanto conflito entre o arquivo de conhecimentos que representam o mundo e as experiências desse mundo, enfim, enquanto confronto permanente e irresolúvel entre pensamento e ação, crítica e experimentação, tradição e acontecimento, ou dito ainda de outro modo, entre espaço e lugares, entre representação e prática4.

Evitando contribuir para a falaciosa dualidade que separa uma "cultura popular progressiva" e uma "arte erudita repressiva" para que nos alerta Mirzoeff (1999, p. 12), privilegiamos as zonas de instabilidade, as regiões de convergência entre estes extremos: é vocação da Passeio, faz parte da sua tomada de posição política, dedicar especial atenção e reflexão crítica aos momentos em que o olhar anónimo, as pequenas narrativas do transeunte comum e as vivências alternativas da cidade no seu quotidiano desafiam o arquivo do especialista e as categorias das suas instituições, o caleidoscópio do turismo e a repetitiva seriação dos seus must-see, ou ainda a esfera dos média e a eventual uniformidade dos seus agendamentos. Estes momentos têm sido analisados por uma vasta literatura no âmbito das ciências da comunicação, sob a terminologia de cultura popular e de cultura visual contemporânea, conceitos que nos cabe reavaliar na segunda parte deste artigo.

\section{Do MUSEU VIRTUAL À PLATAFORMA}

Por fim, o reposicionamento da Passeio passou ainda pela readaptação do âmbito implícito na terminologia de "museu virtual" naquele doravante sugerido pela nomenclatura de "plataforma": quer devido à já referida problemática ancoragem nas ideias de cidade, de arte e de cultura quer devido a uma série de recentes transformações tecnológicas, sociais e culturais, a ideia de "plataforma", que não se esgota na sua aceção informática e que, não por acaso, se encontra hoje em voga nos mais diversos domínios $^{5}$, pareceu-nos, tendo em conta as particularidades da Passeio, não só mais ajustada, como mais abrangente ${ }^{6}$. Enquanto plataforma de arte e cultura urbana, a Passeio

\footnotetext{
${ }_{4}^{4}$ Sintetizamos aqui uma conceção de cultura já desenvolvida em Correia (2013, pp. 79-84).

${ }_{5}^{5}$ Veja-se a este propósito não apenas fenómenos de moda como a propagação atual das "plataformas criativas" na web, mas também a abrangência de infraestruturas como a Plataforma das Artes e da Criatividade em Guimarães.

6 Embora pudéssemos aqui encetar uma certamente instigante releitura da ideia metafórica de "plataforma" à luz das noções de "rizoma", de "liso", ou ainda de "corpo sem órgãos", introduzidas por Gilles Deleuze e Félix Guattari (em Mille Plateaux (1980), a riqueza semântica deste termo já seria bem evidente em qualquer dicionário. Por exemplo, o Dicionário infopédia da Língua Portuguesa com Acordo Ortográfico da Porto Editora define-a assim: "plataforma pla.ta.for. ma plete'forme nome feminino 1. estrutura horizontal, mais ou menos elevada / 2. terraço; açoteia / 3. estrado na parte posterior da locomotiva, onde vai o maquinista / 4. estrado nos carros elétricos, por onde se embarca ou desembarca / 5. estrado elevado à altura do estribo ou do piso dos vagões para facilitar o embarque ou desembarque dos passageiros,
} 
apresenta, então, três eixos de ação, inseparáveis entre si e cuja divisão apenas responde a uma necessidade de sistematização: (1) a investigação e a formação; (2) o arquivo e a divulgação; (3) a colaboração e a extensão.

Do ponto de vista da investigação, a Passeio, por um lado, procurará trabalhar em torno de noções centrais como a cidade, a experiência, o espaço, os lugares e a mobilidade, a cultura visual, a cultura popular, as subculturas, e as minorias, mediante paradigmas teóricos que serão enumerados e sucintamente revisitados ao longo do presente artigo. No que diz respeito ao quadro empírico, a Passeio dirige os seus métodos de investigação, caraterizados por um paradigma qualitativo, uma inspiração antropológica e uma ênfase nas metodologias visuais participativas ${ }^{7}$, para a experiência do local, para a vivência do imediato e para a observação do próximo, estando a sua equipa de investigadores sujeita à condição de proximidade com o terreno empírico: até ao momento, tem-se por isso mesmo, desenvolvido, fundamentalmente, a investigação nas cidades Braga e de Ponta Delgada, cidades de residência das coordenadoras do projeto. Este trabalho de investigação e de produção de conhecimento no domínio da arte e da cultura urbana, que passará por cartografar equipas e projetos científicos relacionados, articular-se-á ainda, sempre que possível, com ações pedagógicas e atividades de formação na área ${ }^{8}$.

Diretamente ligada aos objetivos de investigação e de formação, está ainda a necessidade de constituição de um arquivo e de planificação da sua divulgação. Este arquivo tem-se inspirado em diversas formas, cuja definição e problematização não cabem no presente artigo, mas que passam pelo álbum, a coleção, o calendário, o atlas, o mapa psicogeográfico, o foto-ensaio, o vídeo-ensaio, entre outros. Prevemos que a Passeio divulgue o seu arquivo, de acordo com um modelo de work in progress, através de uma convergência entre as publicações científicas, o site da plataforma - um portal na web, cujo acesso já está previsto na página do CECS -, as redes sociais - às quais este portal estará ligado e que poderão ser redes sociais mais estreitamente associadas à partilha de imagens de cidades, como o Instagram, o Pinterest, o Tumblr, o Flickr, entre outros - e as próprias ruas da cidade ${ }^{9}$. Uma recolha fotográfica exploratória da Passeio pode ser consultada

nas estações dos caminhos de ferro / 6. disco móvel em torno de um eixo central em que se colocam as locomotivas para as mudar de linha / 7. MILITAR estrutura de terra, madeira ou aço sobre a qual assentam as bocas de fogo de artilharia ou quaisquer outros objetos pesados / 8. INFORMÁTICA base composta por hardware, físico ou virtual, pelo sistema operativo, e por aplicações que são a base para o desenvolvimento de novas aplicações / 9. figurado, proposta ou medida conciliatória / 10. figurado, conjunto de ideias ou propostas que constituem a base de uma política comum / 11. figurado, popular simulacro; aparência".

7 Embora os métodos a que recorremos sejam a todo o momento passíveis de redefinição, podemos assumir que a generalidade das táticas metodológicas implementadas e por implementar se coadunam, como referimos, com um paradigma qualitativo, com uma generalizada inspiração antropológica, e com uma especial ênfase nas metodologias visuais participativas. Assim, até ao momento, têm sido usados métodos como a observação - auxiliada pela fotografia, pelo áudio e pelo vídeo - a pesquisa documental (nomeadamente consubstanciada nos recortes de imprensa, num esforço semelhante ao do clipping) a entrevista (com recurso a registos fotográficos e audiovisuais), a história de vida, e finalmente a foto-elicitação, que combina o recurso a imagens fotográficas com a realização da entrevista (Harper, 2002).

${ }^{8}$ Este diálogo já se encontra atualmente em curso através de uma colaboração de discentes do Mestrado em Comunicação, Arte e Cultura da Universidade do Minho na Passeio, como é o caso dos investigadores Fábio Marques e Pauline Protásio.

9 Mediante a importância por nós conferida ao cruzamento dos trajetos quotidianos do navegador na web com os percursos diários do transeunte na cidade, justificar-se-á que a abertura de canais de comunicação on-line seja complementada com um recurso às táticas de divulgação outdoor, implementadas nas ruas das cidades visadas, e que poderiam ter, como 
numa página da Flickr, e as suas localizações sucessivas num mapa colaborativo criado através do My Maps da Google, que tem funcionado como primeiro dispositivo de reunião, de arquivo e de apresentação do material recolhido (Figuras 1 e 2).

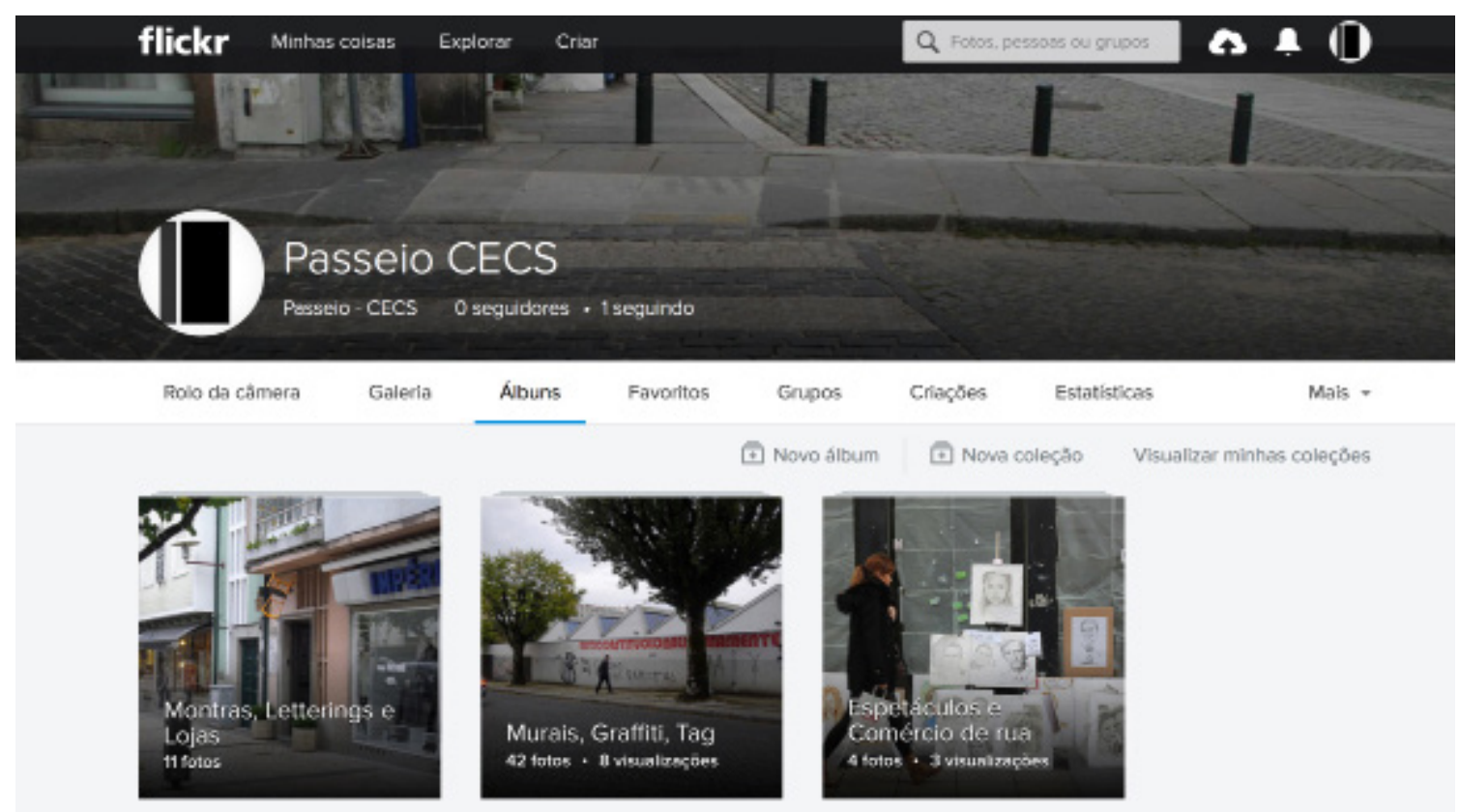

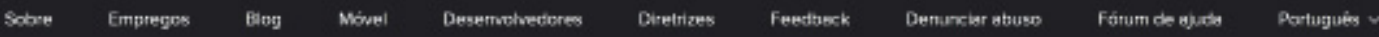

Figura 1: Página Flickr da Passeio com uma primeira recolha de imagens fotográficas para a Passeio, organizadas nas seguintes categorias: (1) Montras, Lettering e Lojas; (2) Murais, Graffiti, Tag; (3) Espetáculos e Comércio de Rua

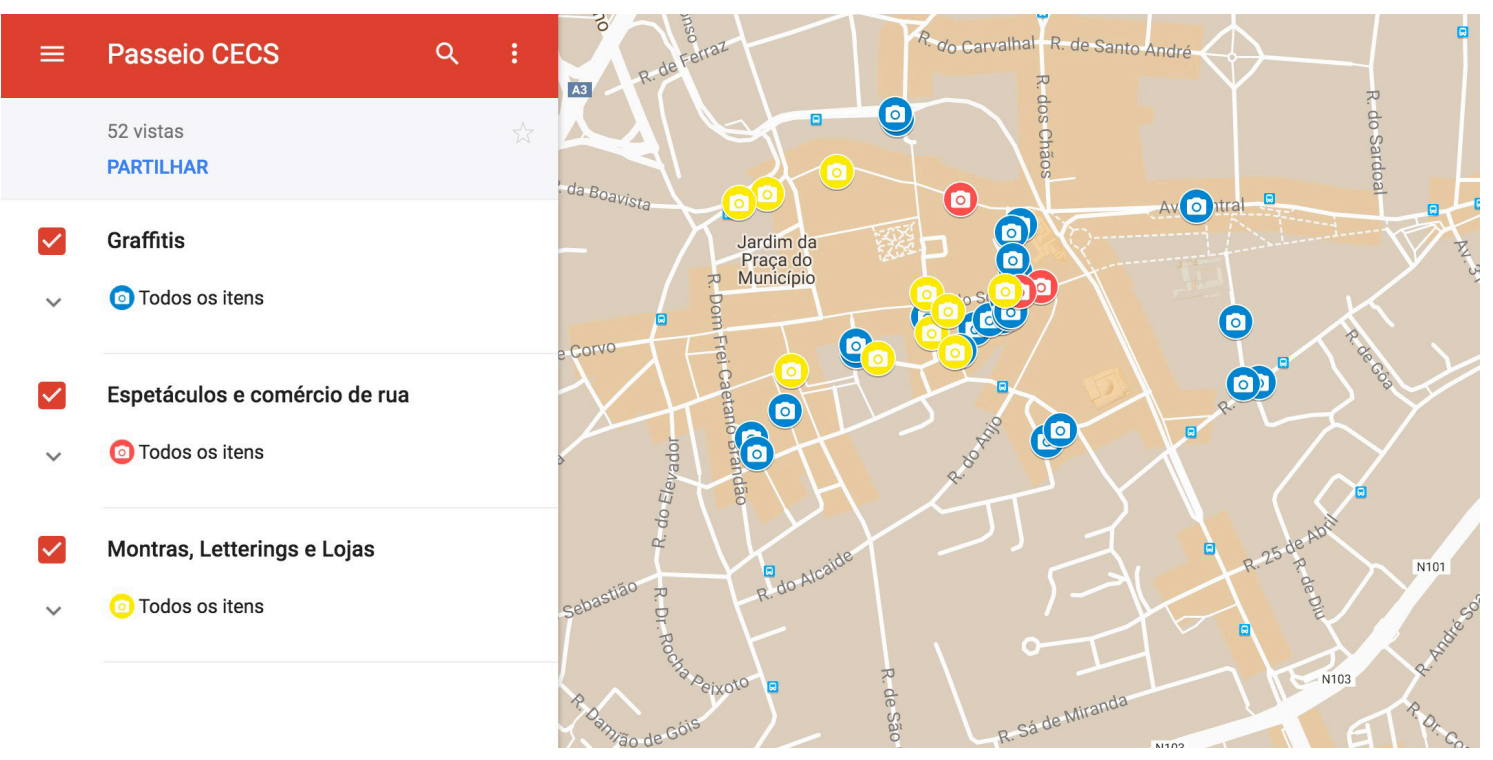

Figura 2: Mapa criado em My Maps da Google a partir da página Flickr da Passeio,cartografando na forma de um percurso as imagens recolhidas em Braga entre 2016 e 2017. A iniciativa e a sua realização é de Fábio Marques, discente do Mestrado em Arte, Comunicação e Cultura e investigador, que tem colaborado na elaboração da plataforma Passeio

exemplo básico, o redireccionamento dos transeuntes da cidade para o portal da Passeio e para as informações aí acessíveis, através da afixação em locais precisos de um código QR. 
Por fim, aliada aos esforços de investigação, de formação, de arquivo e de divulgação, salienta-se a vocação colaborativa desta plataforma, já implícita nos parágrafos anteriores. Com efeito, a ênfase dada ao par da investigação e da formação, o relevo atribuído às metodologias participativas, e ainda a importância conferida às tecnologias digitais e ao seu potencial interativo, são alguns dos aspetos que garantem que a plataforma Passeio esteja aberta a uma prática colaborativa, não se confinando a um rumo absolutamente pré-definido. Esta dimensão colaborativa é reforçada pela ligação estreita com os territórios urbanos da pesquisa de terreno, que faz com que, a par dos seus objetivos científicos, a Passeio tenha ainda um horizonte de extensão cultural e de extensão à comunidade.

\section{PASSEIO, CIDAdE E CULTURA VISUAL: FRONTEIRAS}

Como a sua designação indica, a Passeio parte dessa tendência generalizada, para, a partir do final do século XIX e do início do século XX, pensar a cidade e as imagens que a habitam, refletir sobre a experiência de deambulação do transeunte num labirinto urbano que é doravante complexificado pelas mais diversas tecnologias: automóveis, eletricidade, telégrafo, cartazes publicitários, espetáculos... As imagens da cidade, que também designaremos pelo mais lato termo de cultura visual contemporânea, não são aqui entendidas num sentido restrito, mas integram a experiência multissensorial e psíquica que é apanágio de uma cultura urbana fragmentada, na qual o movimento, a circulação e o trânsito não dizem apenas respeito aos automóveis, às multidões ou aos outdoors publicitários com que se cruza o seu transeunte quotidiano mas também às sensações, ao imaginário e às memórias e narrativas que diariamente o atravessam ${ }^{10}$. Esta tendência para pensar a cidade e as imagens que a habitam, que assumimos desde já como princípio orientador da Passeio, e que aproxima o papel do investigador ao perfil do flâneur, encontra no filósofo alemão Walter Benjamin uma das suas principais inspirações.

Com o seu célebre diagnóstico da perda de aura da obra de arte, Walter Benjamin é um dos primeiros pensadores a assinalar a profunda rutura tecnológica, social e cultural ocorrida no final do século XIX que associa nomeadamente à generalização das técnicas de reprodução como a fotografia e o cinema e que estaria na base do nosso presente entendimento de cultura visual contemporânea. Ao contrário do que sugerem algumas leituras do texto A obra de arte na era da sua reprodutibilidade técnica, Walter Benjamin (1936-1939/2012) não enceta aí o lamento de uma velha aura decadente e perdida, mas identifica, sim, essa rutura - tecnológica, social e cultural - que está na origem das "artes de massas", das "artes montáveis", das artes que seriam, nas suas palavras, as "mais revolucionárias da sua época" e que corresponderiam àquelas a que dedicaria grande parte da sua obra: a fotografia, o cinema e a publicidade.

O filósofo alemão é também pioneiro na postura epistemológica adotada em função deste diagnóstico. Além da sua valorização da "arte popular anónima”, a sua

10 Sobre as relações do visual com o sentido do movimento, do tato, do olfato e da audição, assim como com perturbações psíquicas diversas, veja-se a contribuição de J. W. T. Michell (2002). 
minuciosa descrição de cidades europeias, nomeadamente no seu livro das passagens, aí sustentada por uma defesa metodológica da imagem" e por uma conceção política do papel do historiador ${ }^{12}$, é um dos mais evidentes exemplos. Com efeito, Benjamin assumiu positivamente o papel de flâneur - esse "botânico do asfalto" como o designa - nas metrópoles do seu tempo - de Berlim, a Paris, a Moscovo -, deambulando escrupulosamente entre as galerias comerciais, os cartazes publicitários, as montras e os espelhos, os brinquedos e os autómatos, os postais e as caricaturas, os panoramas, os dioramas, os museus de cera e as exposições universais. Mais passeante do que passante, diferente da multidão em "choque" quer pelo vagar ocioso quer pela solidão distanciada, recompondo no seu labiríntico trajeto a miríade de imagens da City, o flâneur, é uma figura-chave, então, na definição da plataforma Passeio.

Se se deve fazer remontar a Walter Benjamin, e num sentido mais lato à Escola de Frankfurt, o estudo da cidade e do comércio social iconográfico que lhe está associado, não se pode deixar de reconhecer noutras tradições disciplinares o seu determinante contributo. Ainda no âmbito das ciências da comunicação, refira-se o papel fundamental da Escola de Chicago, que escolhe a cidade como seu laboratório sociológico, aí dando enfoque às minorias culturais e étnicas, à marginalidade e às subculturas ${ }^{13}$, com um programa metodológico de inspiração etnográfica e antropológica, que, com diferentes pretextos e em diversas ocasiões, demonstra ainda uma atenção especial à componente não verbal da comunicação (Park, Burgess \& Mckenzie, 1984).

Também importante tem sido o contributo do pós-estruturalismo francês, que tem na obra de Roland Barthes um exemplo ilustrativo. Com uma abordagem que foi por vezes apelidada de semiótica leve das imagens, Roland Barthes ocupou-se de temas tão diversos como a literatura, a fotografia, a moda e a publicidade, tendo homenageado nas suas Mitologias os mais banais objetos da cultura popular: o automóvel, os guias

\footnotetext{
"A valorização metodológica da imagem em Walter Benjamin é sobretudo desenvolvida a partir da noção de "imagem dialética", explicitada no texto Reflexões teóricas sobre o conhecimento, teoria do progresso, no qual Walter Benjamin se propõe a "a dar às datas a sua fisionomia" (1989, p. 494, N11, 2), e em que explora o papel da imagem no conhecimento histórico. Escolhendo a montagem como método, Benjamin pretende ver a história "de maneira estereoscópica“, mostrando-a mais do que dizendo-a, desagregando-o a reagregando-a em imagens (Benjamin, 1989, p. 474, N1, 8). A imagem dialética, elemento central do método benjaminiano, é por ele assim definida: "uma imagem (...) é esse momento no qual o Outrora encontra o Agora num clarão para formar uma constelação. (...) A imagem é a dialética em suspenso". Como se concedesse uma vida e um movimento próprios às imagens, Walter Benjamin nota que a marca histórica das imagens não tem a ver com a época em que estas se inscrevem cronologicamente, mas antes com o momento em que elas alcançam a sua legibilidade, espécie de ponto crítico em que a verdade destas explode. Comparando esse momento com o intervalo entre o sono e a vigília, e abrindo um paralelismo entre a tarefa do historiador e a tarefa do intérprete dos sonhos, Walter Benjamin integra assim também o inconsciente, o onírico e o fantástico na história.

${ }^{12}$ Para Walter Benjamin, o historiador do contemporâneo é um fisionomista dos pequenos momentos, das ninharias do tempo, dos restos da história (1989, pp. 476; 477; N1a, 8; N2, 6) que não deixam de ser contrapostos a uma visão mais geral do seu tempo. É certamente por ser um olhador do minúsculo no meio da maiúscula crise da sua época, que Benjamin propõe aos seus contemporâneos "desenrascar-se como podem, repartir do pé para a mão e com pouca coisa" (Benjamin, 2000a, p. 366) Mais do que aos génios, aos reconhecidos e aos chefes, o contemporâneo pertence, segundo Walter Benjamin, aos homens "anónimos" e "sem nome" e a história que lhes é dedicada contribuiria para "humanizar a humanidade" (Benjamin, 1940/1991, p. 455; 1940/200ob, p. 225).

${ }^{13}$ Sobre a noção de "subcultura", que será certamente fundamental na delimitação dos objetos de investigação e de arquivo da plataforma Passeio, e sobre a importante contribuição para o seu estudo quer da Escola de Chicago quer da Escola de Birmingham (correspondente à tradição dos Estudos Culturais), veja-se nomeadamente a antologia de textos organizada por Sarah Thornton e Ken Gelder, sob o título The subcultures reader (Gelder \& Thornton, 1997).
} 
turísticos, o music-hall, o strip-tease, as revistas de culinária (Barthes, 1957)... Ainda no quadro do pós-estruturalismo francês, foi igualmente preponderante o contributo de Michel Foucault, cuja introdução da teoria da vigilância (Foucault, 1975) e a proposta da noção de heterotopia (Foucault, 1984), entre inúmeros outros contributos, colocariam até hoje questões incontornáveis em qualquer exercício de reflexão sobre a cidade e a sua cultura visual.

Igualmente significativa para a temática da cidade e do seu comércio social de imagens, é, sem dúvida, a tradição dos Estudos Culturais, que tem complexificado o debate em torno da arte e da cultura popular (Hall, 2003), e que tem exercido, na derivação dos visual culture studies, formação disciplinar vanguardista dos anos 9o, uma influência determinante na valorização de uma experiência visual quotidiana e "não estruturada" (Mirzoeff, 1999, p. 7), que encontra nas ruas da cidade uma das suas principais arenas. Tendo desencadeado as mais diversas polémicas e as mais difusas antipatias, nomeadamente aquando do grandiloquente anúncio de um iconic turn (Bohem, 1994; Didi-Huberman, 2008; Mitchell, 1994), os visual culture studies têm, apesar disso, o mérito de muito ter contribuído para problematizar o papel da imagem na totalidade da vida social, questionando nomeadamente a relação entre a imagem e a palavra, a iconografia e a tecnologia, a experiência visual e as correlativas vivências táteis, cinéticas, auditivas, olfativas e psíquicas (Mitchell, 2002), ou a tensão entre as estratégias dos produtores de imagens e as táticas dos seus consumidores (Correia, 2013, pp. 85-89).

Por fim, pense-se ainda na sociologia do imaginário, que teve no sociólogo alemão Georg Simmel (cuja ligação à já referida Escola de Chicago é também conhecida), uma das suas principais inspirações, e que não se pautou apenas por uma reabilitação da imagem enquanto fonte de conhecimento como também por um exaustivo trabalho de reflexão, tão científico quanto poético, sobre a cidade e a sua experiência (Simmel, 1990, 1997). Além do contributo simmeliano, vejam-se, entre outros, os trabalhos de Gaston Bachelard e de Pierre Sansot neste domínio (Bachelard, 1995; Sansot, 2004). Ligados à sociologia do imaginário, estão ainda os campos do saber da antropologia, da psicanálise e da fenomenologia, que não só têm contribuído para o entendimento dessa terra incógnita das imagens, dos sonhos e dos mitos, como têm favorecido uma série de reflexões sobre a cidade e o espaço urbano, as suas representações e a sua experiência, conforme se recapitula, aliás, na terceira parte deste artigo.

A este estado da arte, será ainda de acrescentar que a equipa responsável pela plataforma Passeio tem já trabalhado igualmente a iconografia social quotidiana e o seu vínculo à cidade, tendo nomeadamente as suas coordenadoras integrado o projeto de investigação "Postais Ilustrados para uma socio-semiótica da imagem e do imaginário", financiado pela Fundação para a Ciência e a Tecnologia (PTDC/CCl/2770/2006), em curso no CECS entre 2007 e 2012 e coordenado por Moisés de Lemos Martins. A equipa da plataforma Passeio tem, de diferentes modos, questionado a cultura visual contemporânea, no quadro da relação entre a cidade e os seus transeuntes, ora fixando a sua atenção nos postais ilustrados (Correia, 2013; Martins \& Correia, 2015; Martins \& Oliveira, 2011; Pires, 2015), ora pensando a relação das experiências da viagem e da coleção com 
os meios de comunicação digitais (Correia, 2015a), ora ainda dirigindo o seu olhar para a fotografia recreativa em voga nos centros urbanos do final do séc. XIX e do início do séc. XX (Correia, 2015b, 2016), ora centrando-se ainda no papel da publicidade outdoor na experiência do transeunte da cidade contemporânea (Pires, 2007), ora pensando, por fim, a arte pública e a comunicação pública da arte (Andrade, 2010, 2011).

\section{PASSEIO, ESPAÇO E LUgARES: CONCEITOS E PARAdigmas}

De seguida, iremos cartografar alguns dos conceitos e dos paradigmas teóricos que permitem operacionalizar diferentes aproximações à realidade social do espaço e dos lugares. Temos por intenção discutir a complexidade da natureza que carateriza, precisamente, os laços entre o global e o local, ou seja, os laços entre o(s) espaço(s) e os lugares. $O$ esclarecimento de um dado posicionamento teórico-epistemológico que neste projeto se pretende adotar é tanto mais importante quanto se procura, em última análise, defender uma determinada abordagem metodológica, sendo que o paradigma qualitativo e a inspiração antropológica são as suas principais características.

No final do século XIX e primeira metade do século XX, foram publicados textos no âmbito da sociologia francesa, nomeadamente de Durkheim, Mauss e Halbwachs, especialmente relevantes para a discussão do espaço enquanto categoria mental fundamental ao pensamento ocidental. Importa, assim, considerar o espaço na sua dupla dimensão: enquanto realidade material e social, por um lado, e enquanto representação, por outro.

Durkheim (1912) refere-se ao espaço enquanto "representação coletiva" ou "produto do pensamento coletivo", enquanto modo de dar ordem (Durkheim fala de "coordenação") à experiência sensível. Sendo a heterogeneidade aquilo que carateriza sobremaneira a natureza da realidade social, o espaço poderá então ser entendido enquanto operação de produção de sentido comum e partilhável. Como salienta o autor, é o modelo de organização social que preside ao modelo de organização espacial (Durkheim, 1012, p. 17), havendo uma correspondência entre ambos os modelos.

Mauss (1904/05) perspetiva por sua vez o espaço enquanto dimensão determinada pela vida social (economia, religião...). Deste ponto de vista, o espaço é sobretudo uma realidade material e dinâmica ${ }^{14}$. De ambos os contributos, de Durkheim e Mauss, decorre a complexificação do conceito:

a morfologia (a materialidade), as práticas e as representações passam a surgir como três dimensões mediadas pelo espaço, mas independentes e não necessariamente coincidentes, e, nessa perspetiva, o espaço torna-se num objeto mais complexo, que passa a exigir a presença de múltiplos níveis de análise. (Silvano, 2007, p. 12)

\footnotetext{
${ }^{14}$ Poder-se-á, a partir deste pressuposto, inferir que as transformações no plano objetivo resultam em transformações nas representações coletivas.
} 
Halbwachs, já em 1950, viria a problematizar o espaço na sua relação com a memória coletiva. Em La mémoire collective, precisamente, o autor defende que a memória coletiva e o espaço são mutuamente constituintes. Como falar de memória sem falar do modo como esta se traduz numa dada organização material? Embora se admita a inevitável mutabilidade desse mesmo modo de organização, ao espaço (e à memória) não deixam de estar associadas e estabilidade e a permanência.

Em A Poética do Espaço, de Gaston Bachelard, o sótão ou a cave da casa são lugares de memória e de experiência ${ }^{15}$. Podemos mesmo arriscar dizer que, através da particular e detalhada descrição da estrutura morfológico-poética do espaço vivido, Bachelard (1998) nos apresenta um modelo antropológico elucidativo da complexa dinâmica de potenciação da memória, necessariamente desdobrada na sua dupla estrutura, individual e social, mas também vivida e imaginada.

Já com Lévi-Strauss (1979), a questão que orienta alguns dos seus estudos antropológicos é a de saber que tipo de relação pode existir entre a "configuração espacial" e a "estrutura social". O autor adverte para a complexidade das organizações sociais, consoante os grupos e sub-grupos, uma vez que ao seio de uma mesma cultura correspondem muitas vezes diferentes representações e modelos morfológicos. Embora recusando uma visão simplista sobre uma tal relação entre um modelo e uma dada estrutura social, Lévi-Strauss refere a importância de se pensar a unidade ou diferenciação social na sua correspondência com as representações sociais do espaço. Em particular, é de relevar a proposta do autor, considerando a articulação entre a estrutura social e o espaço, por um lado, e a sua ligação com as identidades coletivas, por outro.

A desvinculação ao "espaço", no quadro da experiência de permanente mobilidade que caracteriza, nos termos de Augé (1992), a "sobremodernidade" ${ }^{16}$, traduz-se num problema, precisamente, de identidade. Partindo do pressuposto de que, numa perspetiva antropológica, a identidade, a história e a relação se co-constituem na sua ligação à edificação do lugar (entendido enquanto lugar de experiência e de memória partilhadas por uma comunidade), Augé propõe o termo "não-lugares" para nomear os lugares de passagem temporária, tais como hotéis, hospitais, aeroportos ${ }^{17}$, com os quais os indivíduos, frequentemente na condição de viajantes, não estabelecem qualquer tipo de laço social duradouro. No decurso do seu texto, Augé (1992) antecipa-se a uma eventual visão precipitada e simplista do problema, chamando a atenção para a importância de

\footnotetext{
${ }^{15}$ Leia-se o seguinte excerto: "a casa não vive somente no dia-a-dia, no curso de uma história, na narrativa de nossa história. Pelos sonhos, as diversas moradas de nossa vida se interpenetram e guardam os tesouros dos dias antigos. Quando, na nova casa, retornam as lembranças das antigas moradas, transportamo-nos ao país da Infância Imóvel, imóvel como o Imemorial" (Bachelard, 1998, p. 25). Esta passagem poderá ilustrar a relação entre a espacialização e a lembrança, embora se admita que o problema do espaço possa ser perspetivado por meio de abordagens muito diversas, nomeadamente enquanto categoria mental nem sempre coincidente com os lugares enquanto plano do vivido e da experiência.
}

${ }^{16}$ Augé (1994) define a sobremodernidade referindo-se a "três figuras de excesso": excesso de tempo (a aceleração da história tudo transformou em acontecimento, esvaziando-se assim de sentido a própria natureza verdadeiramente evenemencial do "acontecimento"); excesso de espaço (a euforia da "globalização" traduz-se, afinal, num "encolhimento"); excesso de individualismo (as referências coletivas, das quais se distinguem os grupos de pertença, deixam de ditar as relações dos indivíduos com o mundo). Ver Silvano (2007, p. 79).

17 No seu livro que sucede a Non-Lieux, intitulado Les sens des autres, Augé (1994) dá outros exemplos de não-lugares, de entre os quais aqui destacamos, pela sua atualidade mediática, os campos de refugiados. 
se pensar a relação entre o espaço (o não-lugar) e o lugar. Mesmo na impossibilidade do lugar, o indivíduo sonha com lugares outros, ao mesmo tempo que, arriscamos dizer (estendendo o pensamento do autor ${ }^{18}$ ), reinventa novas possibilidades de transformar o espaço, ainda que temporariamente vivido.

A natureza particular do espaço da cidade ${ }^{19}$ apela a uma abordagem metodológica específica. Ou seja, a construção de conhecimento sobre a cultura de uma sociedade, de uma comunidade ou de uma época, tendo por base a sua expressão na respetiva cultural material, exige, impreterivelmente, a consideração da transitoriedade das práticas sociais. Já Simmel (1908) se mostrava especialmente atento à mobilidade, nomeadamente à experiência da alteridade, incorporada na figura do estrangeiro, a qual nas cidades encontra, por excelência, intensa expressão. No seu sentido mais amplo, e mesmo metafórico - sendo que "estrangeiro" define, em última análise, a condição de mobilidade no espaço urbano -, uma tal figura é caracterizada pela pluralidade identitária (condição que a todos é comum), importando nesta perspetiva cartografar as proximidades e as distâncias, reatadas na figura do estrangeiro.

Também Benjamin (1989), retomando o pensamento de Simmel, se entrega a um exercício metodológico e reflexivo que visa captar o espírito da modernidade, por meio daquilo que se apresenta ao olhar enquanto aparentemente insignificante, até porque de caráter temporário. A figura do passeante (em lugar do viajante, de que fala Simmel), herdada da poesia de Baudelaire, representa para Benjamin o sujeito solitário e anónimo, esquecido no meio da multidão, ao mesmo tempo que dedicado à observação dos mais ínfimos detalhes, nos quais a cultura se materializa.

A relação do espaço com a cultura contemporânea é igualmente objeto privilegiado de discussão em Lefebvre, na sua conhecida obra, precisamente intitulada A produção do espaço. Aí o autor defende a autonomização do espaço (em relação ao espaço mental e ao espaço físico), definindo-o enquanto constituído pelas práticas sociais (ou seja, pela interação dos sujeitos com o espaço).

Foucault, por seu turno, propõe a noção de espaço de colocação (emplacement) para designar a variedade das relações que constituem os lugares. Como refere o autor, "a colocação define-se pelas relações de vizinhança entre pontos ou elementos" (Foucault, 1985, p. 5). Tais colocações, ou emplacements, desdobram-se em: lugares de passagem - ruas, comboios; lugares de paragem provisória - cafés, cinemas, praias; ou lugares de repouso - casa, quarto.

É precisamente com base no pressuposto da natureza diversa de tais "colocações" (e sobretudo tendo em conta o seu carácter móvel) que, fazendo crítica das abordagens metodológicas e epistemológicas tradicionais da antropologia e etnografia, Appadurai (1997) propõe a noção de fronteira enquanto figura espacial expressiva das condições de mobilidade na contemporaneidade (afinal de contas, condição universal, do presente, mas também do passado, que se contrapõe à "falsa" ideia dos nativos e respetiva

\footnotetext{
${ }^{18}$ Tendo em conta, sobretudo, a publicação que se seguiu a Non-Lieux, intitulada Les sens des autres (1994).

${ }^{19}$ Note-se que no projeto Passeio esta condição é fundamental.
} 
vinculação ao lugar), "tida não como uma linha que separa espaços estáveis, mas como um espaço intermédio, derrapante, poroso" (Silvano, 2007, p. 85). Nesta perspetiva, ao autor encontra-se associada a noção de ethnoscapes ${ }^{20}$ :

Por "ethnoscape", eu entendo a paisagem de pessoas que constroem os mundos mutáveis em que vivem (turistas, imigrantes, refugiados, exilados, trabalhadores estrangeiros e outros grupos e indivíduos móveis), constituem uma característica essencial do mundo e aparecem para afetar a política das (e entre) nações, num grau até aqui sem precedentes. Com isto não quero dizer que não existem comunidades relativamente estáveis, tal como redes de casamentos, amigos, trabalho e lazer, ou formas de filiação por nascimento, residência e outras (Appadurai, 1997, pp. 33-34).

Dos "mundos mutáveis" que designam as novas condições de impermanência, decorre, segundo o autor, a desterritorialização das pesquisas e a procura de novas formas de descrição etnográfica ${ }^{21}$ :

Com grupos migrantes, reagrupados em novas localidades a reconstruir as suas histórias e a reconfigurar os seus projetos étnicos, o ethno em etnografia toma forma num deslize, numa qualidade não localizada. As práticas descritivas da antropologia têm de responder a tudo isso (Appadurai, 1997, p. 48).

Traçada uma breve cartografia respeitante aos contributos que os diferentes autores nos oferecem, tendo em vista refletir sobre as implicações que as mais variadas aceções dos conceitos de espaço e de lugar produzem na construção de conhecimento sobre a relação entre as representações, o imaginário e as práticas sociais, propomo-nos, de seguida, esclarecer algumas das opções metodológicas que pautam a Passeio. Nomeadamente, importa clarificar de que modo se operacionaliza, no terreno, uma aproximação aos atores sociais, bem como aos laços (e desvinculações) que os posicionam face às múltiplas configurações morfológicas e espaciais.

Consideremos a seguinte proposta de Lefebvre (1986) relativa a três conceitos ou três momentos de uma relação dialética (o percecionado, o concebido, o vivido), em suma, a prática social, a representação do espaço e o espaço de representação:

a) Prática social:

engloba a produção e a reprodução dos lugares e dos conjuntos espaciais próprios a cada formação social. Cada membro de uma sociedade é dotado de uma competência (espacial) e de uma performance (espacial) (no sentido que a linguagem dá a estes termos) específicas, que organizam as suas práticas sociais. (Silvano, 2007, p. 44)

\footnotetext{
20 "O sufixo - scape pretende assinalar o caracter fluído das paisagens a que se referem, assim como o facto das relações que as integram se revelarem diferentes conforme o ângulo utilizado para as olhar" (Silvano, 2007, p. 88).

21 "A desmontagem da ideia de nativo, associada à de lugar, leva Appadurai a apelar para uma desterritorialização da observação e do olhar" (Silvano, 2007, pp. 88-89).
} 
b) Representações do espaço:

estão ligadas às relações de produção e à 'ordem' que estas impõem. Implicam a existência de conhecimentos, signos e códigos específicos. Nesse sentido, a teoria reproduz o processo generativo do espaço. Se este é tido como um produto, então os conhecimentos que temos sobre ele estão associados, na medida em que o reproduzem, ao processo de produção do espaço de uma dada sociedade (Silvano, 2007, p. 44);

c) Espaços de representação:

estão, para Lefebvre associados ao quotidiano e ao vivido, ao lado clandestino e subterrâneo da vida social. É aqui que o autor abre perspetivas para o estudo de dimensões menos evidentes - para Lefebvre o espaço é vivido antes de ser percecionado - e, no entanto, absolutamente essenciais, visto que nos permitem chegar a um espaço que se produz e reproduz à margem das grandes obras e que, por isso, também fica à margem das teorias mais globalizantes (Silvano, 2007, p. 44) ${ }^{22}$

É sobretudo no quadro de uma abordagem aos espaços do quotidiano, em afinidade com os espaços de representação e do vivido de que nos fala Lefebvre (1986), que a Passeio se posiciona. A ideia de que o "espaço" se define enquanto abstração, associada à extensividade e à mensurabilidade (a que não são alheias a cartografia e a geometria), em oposição ao "lugar", tido como mais concreto e, em particular, enquanto instância do vivido, tornou-se um lugar-comum ${ }^{23}$. A Passeio visa, porém, concorrer para a desconstrução de uma tal dialética, interessando-lhe a incidência nas diversas gradações intersticiais, tal qual operadas, de modo tanto intensivo quanto deslizante, entre as representações e as práticas. Nesta perspetiva, o espaço e os lugares são neste projeto entendidos enquanto coordenadas moventes que nos permitem, por um lado, uma aproximação ao permanente devir do mundo sensível, por outro, aos quadros de referência culturais e simbólicos que agenciam ao mesmo tempo que são agenciados (n) a produção do espaço.

Enfim, na Passeio, assumimos o papel do investigador-passeante, especialmente atento à vida de rua e à interseção entre as diferentes escalas morfológico-espaciais, tanto reais quanto imaginárias. Isto é, tendo por base de inspiração, designadamente, a abordagem benjaminiana, procuramos ser sensíveis ao modo como se intersetam o longínquo e o próximo, o global e o local, a cultura e o detalhe dos signos e objetos, tais como a arquitetura, os letreiros, mas também as experiências do quotidiano, as conversas de passagem, as histórias de vida do habitante ou viajante anónimo que circula pela cidade.

\footnotetext{
${ }^{22}$ A propósito da concetualização do espaço e dos espaços possíveis, Lefebvre refere-se ao espaço diferencial, "aquele que realmente temos e que resulta da composição de diferentes lugares" (Silvano, 2007, p. 46).

${ }^{23}$ Sobre a necessidade de desconstruir uma dada noção de "espaço" fala, nomeadamente, Bragança de Miranda (2007).
} 


\section{REFERÊNCIAS BIBLIOGRÁFICAS}

Andrade, P. (Ed.) (2011). Comunicação pública da arte: o caso dos museus de arte locais / globais. Lisboa: Edições Caleidoscópio.

Andrade, P.; Marques, C. A. \& Barros, J. da C. (2010). Arte pública e cidadania: novas leituras na cidade criativa. Lisboa: Editora Caleidoscópio.

Appadurai, A. (1997). Modernity at large. Minneapolis: University of Minnesota Press.

Arendt, H. (1972). La crise de la culture. Huit exercices de pensée politique. Paris: Éditions Gallimard.

Artaud, A. (1964). Le théâtre et son double. Paris: Éditions Gallimard.

Augé, M. (1992). Non-lieux: Introduction à une anthropologie de la Surmodernité. Paris: Seuil.

Augé, M. (1994). Les sens des autres. Paris: Fayard.

Bachelard, G. (1998). A poética do espaço. São Paulo: Martins Fontes.

Barthes, R. (1957). Mythologies. Paris: Éditions du Seuil.

Benjamin, W. (1989). Paris, capitale du XIX Siècle: Le livre des passages. Paris: Éditions du Cerf.

Benjamin, W. (1940/1991). Sur le concept d'histoire. In W. Benjamin, Écrits Français (pp. 425-455). Paris: Éditions Gallimard.

Benjamin, W. (2000a). Expérience et pauvreté. In W. Benjamin, Oeuvres II (pp. 364-372). Paris: Gallimard.

Benjamin, W. (1940/200ob). Sur quelques thémes baudelairiens. In W. Benjamin, Oeuvres III (pp.329-390). Paris: Éditions Gallimard.

Benjamin, W. (1936-1939/2012). A obra de arte na era da sua reprodutibilidade técnica. In W. Benjamin, Sobre Arte, Técnica, Linguagem e Política (pp. 59-95). Lisboa: Relógio d'Água.

Bruno, G. (2002). Atlas of emotion - Journeys in art, architecture, and film. Nova lorque: Verso.

Bohem, G. (1994). Die wiederkehr der bilder. In G. Bohem, Was Ist Ein Bild (pp. 11-38). Munique: Wilhelm Fink Verlag.

Correia, M. L. (2013). Intermitências na cultura visual contemporânea: o postal ilustrado e a imagem recreativa. Tese de doutoramento, Universidade do Minho, Braga, Portugal e Universidade Paris V, Sorbonne, Paris, França. Retirado de http://repositorium.sdum.uminho.pt/xmlui/handle/1822/29216

Correia, M. L. (2015a). Recreações da viagem: o desejo de exótico e os novos média. Communication, Technologie Et Développement, 2. Retirado de http://www.comtecdev.com/fr/telecharger/Correia.pdf

Correia, M. L. (2015b). Futurografia: as cidades imaginárias na fotomontagem. In L. Leitão, \& J. Leite, J. (Eds.), Discutindo o Imaginário (pp. 169-192). Recife: Editora UFPE.

Correia, M. L. (2016). Os jogos da imagem: fotografia de atrações. In M. T. Cruz, M. A. Babo, \& J. G. Pinto (Eds.), Tecnologias Culturais e Artes dos Média. Lisboa: CECL, Unyleya.

Cruz, M. T. (1992). Arte e experiência estética. In I. Conde (Ed.), Percepção Estética e Públicos da Cultura (pp. 44-6o). Lisboa: ACARTE, Fundação Calouste Gulbenkian.

Deleuze, G. \& Guattari, F. (1980). Mille plateaux. Capitalisme et schizophrénie II. Paris: Les Éditions de Minuit. 
Didi-Huberman, G. (2008). En ordre dispersé. Trivium, 1. Retirado de http://trivium.revues.org/351

Durkheim, É. (1979). Les formes elémentaires de la vie religieuse, La vie religieuse. Paris: PUF.

Foucault, M. (1984). Des espaces autres. Archi Bref, 48, 5-8.

Foucault, M. (1975). Surveiller et punir, naissance de la prison. Paris: Éditions Gallimard.

Gelder, K. \& Thornton, S. (1997), The subcultures reader. Londres e Nova lorque: Routledge.

Halbwachs, M. (1950). La mémoire collective. Paris: PUF.

Hall, S. (2003). Notas sobre a desconstrução do popular. In L. Sovik (Ed.), Da Diáspora: Identidades e Mediações Culturais (pp. 231-247). Belo Horizonte: UFMG.

Lefebvre, H. (1986). La production de l'espace. Paris: Anthropos.

Lévi-Strauss, C. (1979). Tristes trópicos. Lisboa: Edições 70.

Martins, M. L. (2011). Crise no castelo da cultura. Das estrelas para os ecrãs. Coimbra: Grácio Editor.

Martins, M. L. \& Correia, M. L. (Eds.) (2015). Do post ao postal. Famalicão: Humus.

Martins, M. L. \& Oliveira, M. (Eds.) (2011). Portugal ilustrado em postais - Viana do Castelo, Braga, Bragança, Viseu e Portalegre. Braga: CECS. Retirado de http://hdl.handle.net/1822/36492

Mauss, M. (1974). Ensaio sobre as variações sazoneiras das sociedades esquimó. Sociologia e Antropologia, 2, 237-331.

Miranda, J. A. B. (2007). Teoria da cultura. Lisboa: Edições Século XXI.

Mirzoeff, N. (1999). An introduction to visual culture. Londres e Nova lorque: Routledge.

Mitchell, W. J. T. (2002). Showing seeing: a critique of visual culture. Journal of Visual Culture, 1(2), 165-181.

Park, R. E.; Burgess, E. W. \& McKenzie R. D. (1984). The city: Suggestions for the investigation of human behavior in the city environment. Chicago: University of Chicago Press.

Pires, H. (2007). Gritos na paisagem do nosso interior. A publicidade outdoors e a experiência sensível, nos percursos do quotidiano. À deriva por entre lugares imaginários. Tese de doutoramento, Universidade do Minho, Braga, Portugal. Retirado de http://repositorium.sdum.uminho.pt/handle/1822/7100

Pires, H. (2011). O real emoldurado. M. L. Martins \& M. L. Correia (Ed.), Do Post ao Postal (pp. 61-74) Famalicão: Humus.

Sansot, P. (2004). Poétique de la ville. Paris: Éditions Payot \& Rivages.

Silvano, F. (2007). Antropologia do espaço, uma introdução. Oeiras: Celta.

Simmel, G. (1990). Digressions sur l'étranger. In Y. Grafmeyer \& I. Joseph (Eds.), L'École de Chicago (pp. 5359). Paris: Aubier.

Simmel, G. (1997). A metrópole e a vida do espírito. In C. Fortuna (Ed.), Cidade, Cultura e Globalização: Ensaios de Sociologia (pp. 31-43). Oeiras: Celta Editora. 


\section{NOTAS BIOGRÁFICAS}

Maria da Luz Correia é atualmente Professora Auxiliar no Departamento de Línguas, Literaturas e Culturas na Universidade dos Açores. É doutorada em Ciências da Comunicação, pela Universidade do Minho e em Sociologia, pela Université Paris Descartes - Sorbonne. Investigadora do Centro de Estudos de Comunicação e Sociedade da Universidade do Minho, tem publicado na área da cultura visual, da teoria da imagem e da história da fotografia.

E-mail: mariadaluzcorreia@gmail.com

Centro de Estudos de Comunicação e Sociedade, Instituto de Ciências Sociais, Campus de Gualtar, 4710-057 Braga, Portugal

Helena Pires é Professora Auxiliar no Departamento de Ciências da Comunicação da Universidade do Minho. Doutorou-se em Ciências da Comunicação, na Universidade do Minho, em 2007. É investigadora no Centro de Estudos em Comunicação e Sociedade (CECS - UMinho) e tem publicado sobre paisagem urbana, semiótica, publicidade e arte contemporânea.

E-mail: helena.pires538@gmail.com

Centro de Estudos de Comunicação e Sociedade, Instituto de Ciências Sociais, Campus de Gualtar, 4710-057 Braga, Portugal

Pedro Andrade é Investigador no Centro de Estudos de Comunicação e Sociedade, na Universidade do Minho e os seus principais domínios de investigação são os museus de arte e ciência, comunicações digitais e literacias, redes sociais digitais, metodologias e hipermédia. Doutorou-se em Sociologia da Cultura na Universidade Nova de Lisboa em 2002.

E-mail: pjoandrade@gmail.com

Centro de Estudos de Comunicação e Sociedade, Instituto de Ciências Sociais, Campus de Gualtar, 4710-057 Braga, Portugal

Submetido: $15 / 03 / 2017$

Aceite: 09/05/2017 